Work pressures stemming from school authorities and burnout among physical education teachers: The mediating role of psychological needs thwarting

Franco, E., Cuevas, R., Coterón, J., \& Spray, C.

Journal of Teaching in Physical Education

Date of submission: 02/04/2020

Date of acceptance: 18/01/2021 


\title{
Work pressures stemming from school authorities and burnout among physical education teachers: The mediating role of psychological needs thwarting
}

\begin{abstract}
Purpose: The aim of this study was to examine the role of psychological need thwarting in mediating physical education (PE) teachers' work pressures stemming from school authorities and burnout. Method: A total of 345 PE teachers ( $M=47.46$; $\mathrm{SD}=8.79)$ completed some online validated questionnaires. Results: Structural equation modeling (SEM) first revealed that pressures from school authorities predicted needs thwarting which, in turn, predicted burnout. In a second model, in which burnout was deemed as a multidimensional construct, autonomy and competence thwarting was found to predict both emotional exhaustion and depersonalisation. DiscussionConclusion: These findings suggest that when teachers find themselves pressured by school authorities to act in certain way, they are more likely to feel more exhausted and to adopt more cynical attitudes towards their students due to the thwarting of their basic needs. Practical implications related to school and national policies are discussed.
\end{abstract}

Keywords: Self-determination theory; teacher; basic psychological needs; illbeing; structural equation modeling 
Over the last few decades, teaching has been characterized as a profession that is “emotionally taxing and potentially frustrating" (Lambert, O'Donnell, Kusherman, \& McCarthy, 2006, p.105). Findings from existing literature have revealed that negative experiences in educators' careers might produce psychological disorders such as stress and burnout (García-Carmona, Marín, \& Aguayo, 2019).

Burnout can be defined as a syndrome with physical, emotional, and mental dimensions, including negative attitudes toward life towards other people or towards a career (Akbaba, 2014). Maslach and Leiter (2005) defined burnout as a combination of three components: Emotional exhaustion, lack of personal accomplishment, and depersonalization. "Emotional exhaustion" is the emotional lassitude a person experiences when they are fatigued and frustrated. "Depersonalization," is when a person tends to isolate themselves from others. The final component, "Personal accomplishment" is the person's self-evaluation of their own work. Within the teaching context, burnout consequences seem to affect both institutions (through and individuals (García-Carmona et al., 2019). As for the former, teachers' burnout might affect the efficiency and the daily organization of the schools since, when suffering burnout, teachers might need to be substituted and it can alter the development of the subject syllabus (Prieto \& Bermejo, 2006). Regarding consequences for teachers it has been suggested that the experience of burnout might have a direct influence on teachers' psychological health (Gluschkoff et al., 2016) and quality of life (Kidger et al., 2016)

\section{Burnout in PE teachers}

The unique characteristics of the physical education (PE) context such as the physical structure of the classroom setting (MacDonald, 1995), the development of potentially dangerous activities (Spittle, Kremer, \& Sullivan, 2015), the wide range of occupational duties (O'Connor \& Macdonald, 2002), or the status of the teacher and the 
subject (Kougioumtzis, Patriksson, \& Stråhlman, 2011) warrants the growing interest in gaining understanding about PE teachers' negative experiences. Previous literature addressing how the unique characteristics of PE context might affect teachers' negative individual outcomes have suggested that PE teachers might feel a lack of opportunity to participate in decision-making, limited professional respect, huge workloads or lack of intellectual challenge and direction (Whipp. Tan, and Yeo, 2007). These feelings and perceptions are in line with the experience of burnout as they might well affect their dimensions (e.g., the huge workloads seems to be closely related to the experience of emotional exhaustion).

In the PE setting, teachers' burnout has been associated with certain maladaptive outcomes such anxiety and depression (Abós, Haerens, et al., 2019) or turnover intention (Abós, Haerens, et al., 2019; Lee, 2019) and negatively associated with desirable outcomes such job satisfaction (Koustelios \& Tsigilis, 2005). The influence of burnout experience on teachers' individual outcomes is a strong argument to further explore potential mechanisms and antecedents leading to this state. However, the detrimental effects of experiencing burnout go beyond teachers' feelings and perceptions given that there is also evidence that the burnout experience might lead to the exertion of certain behaviors affecting the learning process. In this respect, it has been suggested that teachers experiencing burnout are less likely to create needsupportive environments (Van den Berghe et al., 2014; Van den Berghe et al., 2013; Smith \& Leng, 2003). Considering the impact of burnout on both teachers' well- and ill-being and on the learning process, it is not surprising the growth of a research line addressing the understanding of underlying factors which might explain the experience of burnout (e.g., Abós, Sevil, Haerens, Aelterman, \& García-González, 2019).

\section{Perceived pressures stemming from school authorities among PE teachers}


Different sources of personal ill-being have been identified in the PE literature. In this line, the findings by Bartholomew, Ntoumanis, Cuevas, and Lonsdale (2014) revealed that work-related pressures perceived by PE teachers would affect their burnout experience. These work-related pressures had been previously identified through a qualitative study in which PE teachers were interviewed (Taylor, Ntoumanis, \& Smith, 2009), and grouped in four different dimensions: pressures stemming from school authorities (e.g., to conform to certain methodologies), pressures stemming from colleagues (e.g., to feel being questioned by colleagues), pressures felt for being evaluated based on their students' performance (e.g. to feel that their success rely on their students' performance), and time constraints (e.g., to feel they have to rush to complete their lessons).

Pressures coming from school authorities refer to what extent teachers feel compelled to act in the manner dictated by their school policy. Feeling obliged to both stick to the prescribed curriculum and to use certain methodologies is reflected in this dimension (see example items in the instruments section). This kind of pressures can be frequently found in the literature. Studies carried out with teachers, regardless of their specialism, have suggested that teachers feel they hold low level of control and power in schools because head-teachers make many decisions for them or because inspections make them feel vulnerable (e.g., Buckley, Abbott, \& Franey, 2017). In this line, aspects such principal's leadership behaviour (e.g., Bottiani, Duran, Pas, \& Bradshaw, 2019) have been suggested to affect burnout among teachers. In the Spanish PE context, there is important evidence suggesting that the need to stick to extremely tight and strict curricular guidelines is a source of pressures for teachers who feel they have little room left for their contributions (Albarracín, Moreno-Murcia, \& Beltrán-Carrillo, 2014; Molina, Valenciano, \& Úbeda-Colomer, 2016). 
Despite increasing interest in the topic, the association between specific pressures stemming from school authorities perceived by PE teachers and the experience of burnout has not received significant attention in the existing literature. Previous works addressing how burnout is influenced by general job pressures (Bartholomew et al., 2014) or by a particular source of pressures (Cuevas, Ntoumanis, Fernandez-Bustos, \& Bartholomew, 2018) have shown that motivational constructs might mediate the relationship between job pressures and burnout. However, to the best of our knowledge, no previous studies have aimed to analyse whether feeling pressured by school authorities to conform to certain methodologies and curriculum might foster the experience of burnout.

\section{Self Determination Theory: The Role of Basic Psychological Needs Thwarting}

The aforementioned studies carried out by Bartholomew et al. (2014) and Cuevas et al. (2018) tested models in which burnout was predicted by pressures through motivational variables from the lens of self-determination theory (SDT; Ryan \& Deci, 2020). SDT distinguishes three basic psychological needs (BPN; autonomy, competence, and relatedness) that are assumed to directly enhance psychological and physical well-being (Vansteenkiste, Ryan, \& Soenens, 2020). Autonomy can be defined as one's need to feel responsible and/or owner of one's own behavior; competence can be fulfilled when experiencing effectiveness in one's interactions with the world; and relatedness refers to a need for connectedness with significant others (Vansteenkiste et al., 2020)

Previous studies have shown a clear association between psychological need satisfaction and well-being and other adaptive outcomes in different contexts (e.g., van Aart, Hartman, Elferink-Gemser, Mombarg, \& Visscher, 2017). However, beyond optimal psychological functioning, SDT recognizes that people can also show patterns 
that represent the darker sides of human development. Such negative outcomes are hypothesized to occur when individuals perceive their psychological needs to be actively undermined in their close social environment (Vansteenkiste et al., 2020). The thwarting of the BPN is not synonymous with low BPN satisfaction, but rather reflects that BPN are being actively frustrated within a given context and there is evidence supporting this differentiation (Stebbings, Taylor, Spray, \& Ntoumanis, 2012).

In accordance with previous studies, the experience of needs thwarting is suggested to be a psychological construct which might help to understand the experience of burnout in different populations (Bartholomew et al., 2014; Bartholomew, Ntoumanis, \& Thogersen-Ntoumani, 2010; Pulido, Sánchez-Oliva, González-Ponce, \& García-Calvo, 2017). In the educational context, teachers may feel their autonomy to be thwarted if they cannot decide their own methodological approaches; might perceive their competence to be undermined if they are not given the opportunity to show their excellence in their field; and, lastly, might think their relatedness is being thwarted if they feel ostracized by their colleagues. Whereas previous studies have suggested that the perception of need thwarting among PE teachers can be associated with the experience of burnout (Bartholomew et al., 2014; Cuevas, Sánchez-Oliva, Bartholomew, Ntoumanis, \& García-Calvo, 2015), only one study has addressed the differential role that the thwarting of each basic need might have on each of burnout dimensions (Sánchez-Oliva, Sánchez-Miguel, Pulido, López-Chamorro, \& Cuevas, 2014).

Given the different nature of each burnout dimension as presented earlier, it came as no surprise that each of them was differently associated with the thwarting of each basic need. Teachers might experience burnout because they feel extremely exhausted even though they do not see themselves as inefficient, and vice-versa. It 
seems reasonable to propose that motives leading to that state and practical implications might vary depending on whether teachers feel exhausted, cynical or inefficient. It would be thus interesting to keep gaining some more fine-grained understanding of the potential antecedents of burnout dimensions such needs thwarting.

\section{The Present Study}

Pressures coming from school authorities seem to be of great concern for Spanish PE teachers (Bartholomew et al., 2014; Sáenz-López, Almagro, \& Ibáñez, 2011). Despite the relevance that these concerns might have on teacher ill-being, these pressures have received little attention in the literature and no previous research aiming to analyze school authorities demands in isolation could be located. The aim of this study was to examine the role of psychological need thwarting in mediating PE teachers' work pressures stemming from school authorities and burnout. First, an explanatory model was examined in which burnout was considered as a unidimensional construct. Second, seeking a better understanding of the process, an alternative model using the three dimensions of burnout proposed by Schaufeli, Leiter, Maslach, and Jackson (1996) was tested. It was hypothesized that job pressure related to school authorities would positively predict thwarting of the three BPN which, in turn, would be associated with unidimensional burnout. For the second model, and due to the lack of existence evidence, no hypotheses were proposed. Whereas the association between perceived job pressures and burnout seems to be widely accepted, identifying which dimensions of burnout are more likely to be affected by the thwarting of BPN would be of great interest to better understand explanatory processes and facilitate interventions in schools to optimize teachers' psychological functioning. Lastly, the invariance across gender and type of school (public and private) of the second hypothesized model was tested. Thus, the specific hypotheses in this study were: 
- The effect of pressures coming from school authorities perceived by PE teachers on their burnout would be mediated by teachers' psychological need thwarting (Model A).

- Burnout dimensions would be differently associated with each of the three psychological need thwarting (Model B).

\section{Method}

\section{Participants}

A convenience sample of 345 PE teachers (220 males and 125 females) aged between 28 and 67 years old $(M=47.46 ; S D=8.79)$ participated in the study. Being a non-probability sampling method, it is widely used in social sciences and can give some meaningful results when the target population is relatively homogeneous (Acharyya \& Bhattacharya, 2020). Teachers were drawn from both public $(\mathrm{n}=318)$ and private $(\mathrm{n}=$ 27) high schools in two Spanish regions (Comunidad de Madrid and Castilla la Mancha). Participants worked both in rural and urban areas and, on average, they had 16.09 years of teaching experience $(\mathrm{SD}=9.12)$.

\section{Measures}

\section{Pressures stemming from school authorities}

A questionnaire to assess four types of work-related pressured experienced by PE teachers was used (Bartholomew et al., 2014). The questionnaire consisted of 16 items (4 per subscale): perceived time constraints (e.g., "I am sometimes rushing to complete my lessons"), pressures stemming from school authorities (e.g., "My teaching methods are dictated by school policy"), pressures stemming from school colleagues (e.g., "I feel my colleagues question my teaching methods") and pressures from being evaluated based on their students' performances (e.g., "If the students don't perform, it 
looks bad on my record"). As it is one of the aims of this study, the aforementioned psychometric properties of this instrument are presented in the Results section.

\section{Psychological need thwarting}

Teachers' perceptions of need thwarting were assessed using an adapted and translated version of the 12-item Psychological Need Thwarting Scale (PNTS; Bartholomew, Ntoumanis, Ryan, \& Thogersen-Ntoumani, 2011), composed by three subscales of 4 items each. The stem used in the questionnaire was "In my PE classes..." and teachers rated the extent to which they felt their psychological needs for autonomy (e.g., "I feel prevented from making choices with regard to the way I teach"), competence (e.g., "situations occur in which I am made to feel inadequate"), and relatedness (e.g., "I feel other people dislike me") were thwarted in the teaching context. The reliability and factorial validity of the PNTS has been supported in Spanish (Cuevas et al., 2015). Cronbach's alphas for each dimension were .88 for autonomy thwarting, .85 for competence thwarting, and .81 for relatedness thwarting.

\section{Burnout}

The 16-item version of the Maslach Burnout Inventory - General Survey (MBIGS; Schaufeli et al., 1996) was used to measure burnout symptoms. The scale contains three subscales measuring exhaustion (five items, e.g., "I feel tired when I get up in the morning and have to face another day on the job"), depersonalization (five items, e.g., "I have become less enthusiastic about my work") and personal accomplishment (six items, e.g., "In my opinion, I am good at my job"). The reliability and factorial validity of the PNTS has been supported in Spanish (Gil-Monte, 2002). Cronbach's alphas for each dimension were .83 for emotional exhaustion, .74 for depersonalisation, and .85 for personal accomplishment. Responses to all the measures were reported on a 7-point scale ranging. from 1 (not at all true) to 7 (very true). 


\section{Procedure}

Back-translation of the items was carried out following the recommendations by Hambleton and Patsula (1998). After receiving approval from the Ethics Committee of two Spanish universities, all participants were treated in agreement with the ethical guidelines of the American Psychological Association American Psychological Association (2002).

On the one hand, an e-mail list from high schools in Castilla la Mancha and Madrid was created. The e-mail addresses were retrieved from the websites of the Education Counseling (Consejería de Educación). Two thousand high schools were contacted through a mail asking for the participation of PE teachers in answering an online Google Form questionnaire and 360 answers were collected (response rate of 18\%). Participants who did not answer all the questions $(n=55)$ were discarded, resulting in a first sample of 305 PE teachers. On the other hand, 48 PE teachers who had previously collaborated in some other research studies were personally addressed through e-mail and asked to participate in the study. Forty of them agreed to take part in the study and answered the Google Form questionnaire. The website provided an explanation of the aim and procedure of the study, asking for the teachers' consent to participate in the study, and offering participants the opportunity to get in touch with the research team in the event of questions. Participants were also informed that the information collected would be treated as confidential and anonymous following the procedure indicated by the Ethics Committee of two Spanish universities.

\section{Data analysis}

Sample size was determined following recommendations by Bentler and Chou (1987). These authors suggested that the ratio should be 5 observations to 1 parameter.

Since 61 parameters were estimated in the most complex model, a minimum sample of 
305 was required. To validate the Job Pressure Scale for PE teachers, an examination of the psychometric properties of the scale was carried out. A confirmatory factor analysis (CFA) was done to confirm the factor structure of the instrument suggested by Bartholomew et al. (2014). Recommendations made by Byrne were followed in the establishment of acceptable criteria. The assessment of the CFA model relied on the following goodness-of-fit indices: the comparative fit index (CFI), the Tucker Lewis index (TLI), the root mean square error of approximation (RMSEA), and the standardized root mean square residual (SRMR). With respect to CFI and TLI, values greater than .90 and .95 indicate appropriate and excellent fit to the data, respectively (Marsh, Hau, \& Wen, 2004) . Regarding RMSEA and SRMR values of .08 or less are considered as acceptable (Browne \& Cudeck, 1993). Convergent and discriminant validity were tested as indicators of construct validity. Convergent validity was considered acceptable when the average variance extracted (AVE) was higher than .50 and the composite score reliability (CR) of each dimension was higher than 0.70 (Hair, Black, Babin, \& Anderson, 2010). However, according to Fornell and Larcker (1981), an AVE lower than 0.5 can still be deemed as adequate provided that $\mathrm{CR}$ is above the threshold. Discriminant validity was supported when the factor loading of an item on its own construct was higher than its cross-loadings in other constructs.

Structural equation modelling was performed to test the hypothesized sequence. The fit of the observed data to the proposed mediation model was calculated with the IBM AMOS 20.0 using the maximum likelihood estimation method; 5000 bootstrapping iterations were requested for the calculation of bias-corrected $95 \%$ confidence intervals (Byrne, 2001). To evaluate the model fit, the CFI, IFI, RMSEA and SRMR were selected and results were assessed using the criteria previously detailed. The procedure followed in the estimation for the latent constructs is presented in the 
Results section. The resulting model was re-analyzed in a multigroup analysis to test its invariance across gender and type of school in which participant teachers worked at. This testing was achieved by comparing the unconstrained multigroup model with models constraining regression weights and covariances. Power analysis to detect target effects were performed through a Monte Carlo simulation approach using the tool developed by Wang (Wang \& Rhemtulla, in press). A simulation with 100 samples was run for $N=345$ and an alpha level of 0.05 . The power to detect the regression coefficients in both models ranged from .78 to .89 .

\section{Results}

Table 1 presents the descriptive statistics, internal reliability estimates, and intercorrelations for all of the scales used to assess the variables in the study. All scales demonstrated Cronbach's Alpha coefficients higher than 0.80 .

Table 1. Descriptive statistics, internal reliabilities, and Pearson correlations for variables

\begin{tabular}{|c|c|c|c|c|c|c|c|c|c|}
\hline Variable & $\begin{array}{l}\text { M } \\
\text { (SD) }\end{array}$ & $\alpha$ & 1 & 2 & 3 & 4 & 5 & 6 & 7 \\
\hline 1. SAP & $\begin{array}{l}2.37 \\
(1.20)\end{array}$ & .75 & & & & & & & \\
\hline 2. Autonomy thwarting & $\begin{array}{l}1.88 \\
(1.25)\end{array}$ & .91 & $.694 *$ & & & & & & \\
\hline 3. Competence thwarting & $\begin{array}{l}2.24 \\
(1.36)\end{array}$ & .85 & $.482 *$ & $.580 *$ & & & & & \\
\hline 4. Relatedness thwarting & $\begin{array}{l}1.79 \\
(1.09)\end{array}$ & .81 & $.479 *$ & $.587 *$ & $.554 *$ & & & & \\
\hline 5. Burnout & $\begin{array}{l}3.69 \\
(.85)\end{array}$ & .79 & $.403 *$ & $.482 *$ & $.483 *$ & $.430 *$ & & & \\
\hline 6. Exhaustion & $\begin{array}{l}2.82 \\
(1.46)\end{array}$ & .89 & $.484 *$ & $.525^{*}$ & $.516^{*}$ & $.429 *$ & $.749 *$ & & \\
\hline 7. Depersonalization & $\begin{array}{l}2.75 \\
(1.37)\end{array}$ & .89 & $.400 *$ & $.504 *$ & $.482 *$ & $.448 *$ & $.824 *$ & $.590 *$ & \\
\hline 8. PA & $\begin{array}{l}5.51 \\
(1.24)\end{array}$ & .81 & $\begin{array}{l}- \\
.185^{*}\end{array}$ & $\begin{array}{l}- \\
.187 *\end{array}$ & $\begin{array}{l}- \\
.150 *\end{array}$ & $\begin{array}{l}- \\
.118^{*}\end{array}$ & $.258 *$ & $\begin{array}{l}- \\
.293 *\end{array}$ & $\begin{array}{l}- \\
.111\end{array}$ \\
\hline
\end{tabular}

Note: $\mathrm{SAP}=$ Pressures stemming from school authorities; $\mathrm{PA}=$ Personal accomplishment; $*=p<.01$ 
Confirmatory Factor Analysis (CFA) with four-factor structure was calculated including the 16 items proposed by Bartholomew et al. (2014) and grouping them in the factors suggested by these authors based on previous research. The indices revealed that this model did not show an adequate fit to the data $\left(\chi^{2}[98]=282.95, \mathrm{p}<.001, \chi^{2} / \mathrm{df}=\right.$ $2.89, \mathrm{CFI}=.85, \mathrm{IFI}=.85, \mathrm{RMSEA}=.07, \mathrm{SRMR}=.06)$. According to Brown's guidelines (2015), factor loadings lower than 0.30 should not be considered as salient. As it is shown in Table 2, all items loaded adequately onto their respective factors except for item one ("My school does not put pressure on me to teach in certain ways"), three ("I teach how I like irrespective of how my colleagues teach") and 15 ("I am held responsible for student performance standards"). Being aware of the problematic underlying reversed worded items, it was decided to delete items one and three (van Sonderen, Sanderman, \& Coyne, 2013). Furthermore, item 15 was revised in depth. This item was expected to load onto the factor "Pressures for being evaluated based on their students' performance". While other items associated with this factor clearly state the underlying idea of pressure with a negative connotation (e.g., "If students don't perform it looks bad on my record"), this does not seem to be so obvious in the item 15 , which rather refers to how responsible the teacher feels about students' performance. Taking this into consideration, it was decided to disregard this item and proceed to reanalyze the model. After the deletion of these three items, the model was tested again and showed a good fit to the data $(\chi 2[59]=155.51, \mathrm{p}<.001, \chi 2 / \mathrm{df}=2.64, \mathrm{CFI}=.91$, $\mathrm{IFI}=.91, \mathrm{RMSEA}=.07, \mathrm{SRMR}=.06)$. As shown in Table $2, \mathrm{CR}$ values were above 0.70 for all the constructs. As for AVE, it was between .37 and .50 .

Table 2. Standardized regression weights of the items on their factors

\begin{tabular}{ccccc}
\hline Factor & Indicators & $\begin{array}{c}\text { Loading } \\
\text { s }\end{array}$ & AVE & CR \\
\hline Perceived time constraints & Item 2 & .342 \\
& Item 5 & .526 & .37 & \multirow{2}{*}{.74} \\
\hline
\end{tabular}




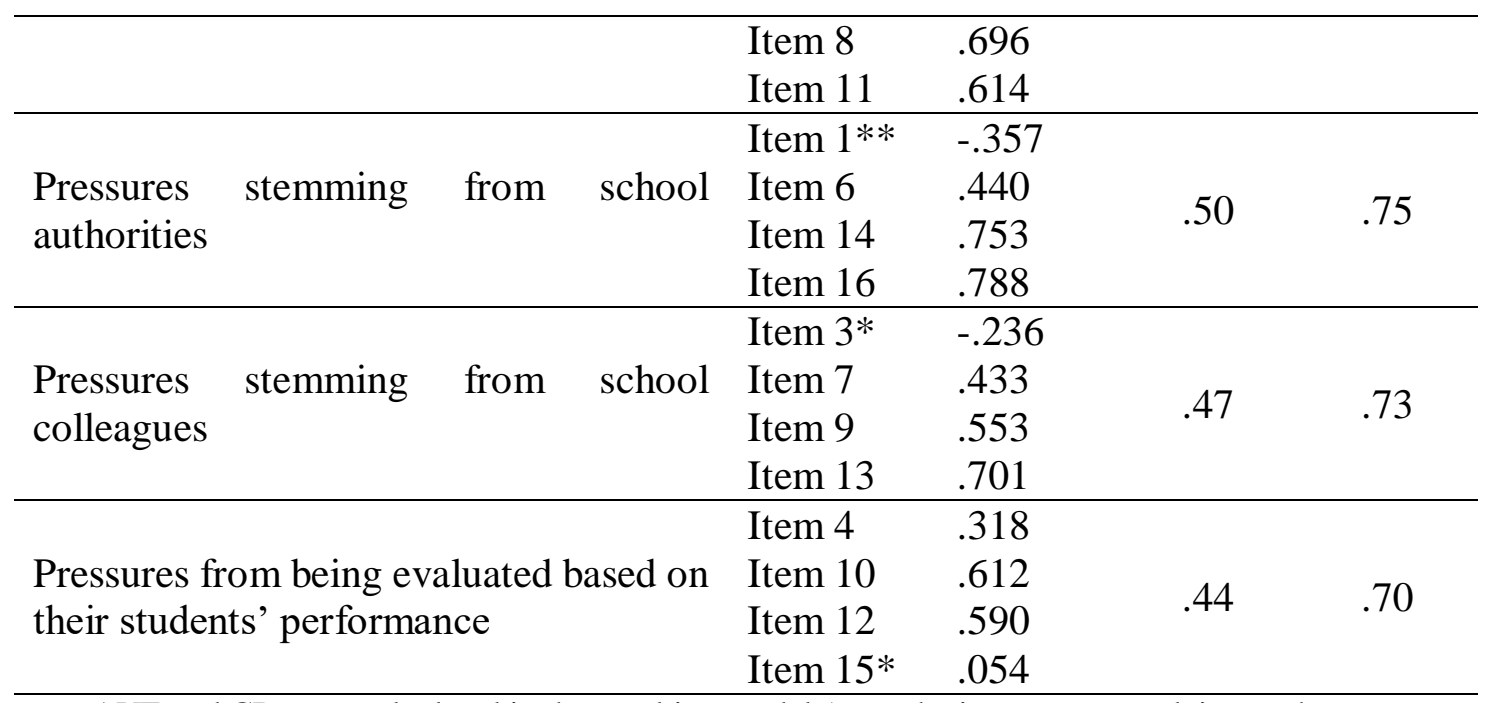

Note. AVE and CR were calculated in the resulting model (once the items not complying to the established conditions had been removed)

* Item with factor loading lower than 0.3

** Items negatively worded and with factor loading lower than 0.3

\section{Explanatory model of Burnout as a unidimensional variable through authorities' pressures and psychological needs thwarting (Model A)}

All constructs were deemed as latent variables in the SEM. To increase the stability of the parameter estimates and improve the ratio of sample size to estimated parameters, construct specific parcels were created in those cases in which the number of items per construct was higher than three (Bagozzi \& Edwards, 1998). Following Matsunaga recommendations (2008; p.282) three parcels per factors were used in the analyses. Each parcel was created by pairing stronger loading items with weaker loading items from the same scale (Little, Cunningham, Shahar, \& Widaman, 2002). When the number of items did not permit the creation of three parcels of two items, one parcel was created by pairing the strongest and the weakest items from a scale and the other items were used as indicators.

The structural model demonstrated a good fit to the data: $\chi^{2}(84)=263.47, \mathrm{p}<$ $.001, \chi 2 / \mathrm{df}=3.14, \mathrm{CFI}=.94, \mathrm{IFI}=.94, \mathrm{RMSEA}=.08, \mathrm{SRMR}=.07$. The standardized path coefficients and variance explained for endogenous variables are presented in Figure 1. Table 3 presents the direct and specific indirect effects transmitted through 
autonomy thwarting, competence thwarting and relatedness thwarting and their $\mathrm{BC}$ $95 \%$.

INSERT FIGURE 1

Table 3. Bootstrap analysis summary showing the direct and indirect effects of school authority pressures on burnout via BPN thwarting (Model A)

\begin{tabular}{lcccc}
\hline & \multicolumn{3}{c}{ Bootstrapping BC 95\% } \\
\hline Path & Estimate & $p$ & Lower & Upper \\
\hline \multicolumn{2}{c}{ Direct effects } \\
\hline SAP - Burnout & -.154 & .737 & -1.651 & .810 \\
SAP - AT & .942 & .001 & .881 & .994 \\
SAP-CT & .646 & .001 & .539 & .739 \\
SAP-RT & .716 & .002 & .592 & .812 \\
AT-Burnout & .380 & .001 & .205 & .566 \\
CT-Burnout & .296 & .001 & .123 & .460 \\
RT-Burnout & .203 & .025 & .023 & .405 \\
\hline \multicolumn{1}{c}{ Indirect effects of School Authority Pressures } & on Teachers Burnout through: \\
\hline AT & .590 & .01 & .289 & 1.039 \\
CT & .315 & .01 & .125 & .565 \\
RT & .239 & .03 & .026 & .534 \\
\hline
\end{tabular}

Note: $\mathrm{SAP}=$ Pressures stemming from school authorities; AT= autonomy thwarting; $\mathrm{CT}=$ competence thwarting; $\mathrm{RT}=$ relatedness thwarting

\section{Explanatory model for three dimensions of Burnout through authorities' pressures} and psychological needs thwarting (Model B)

Three new constructs were included in this model (those corresponding with Burnout dimensions). These constructs were deemed as latent variables. The creation of these variables followed the same procedure previously explained for the autonomy, competence and relatedness need thwarting subscales (Bagozzi \& Edwards, 1998; Little et al., 2002). The structural model demonstrated a good fit to the data: $\chi 2(177)=$ $501.65, \mathrm{p}<.001, \chi 2 / \mathrm{df}=2.83, \mathrm{CFI}=.92, \mathrm{IFI}=.92, \mathrm{RMSEA}=.07, \mathrm{SRMR}=.08$. The 
standardized path coefficients and variance explained for endogenous variables are presented in Figure 2. Specific indirect effects of the model shown in Figure 2 are presented in Table 4.

\section{INSERT FIGURE 2}

Table 4. Bootstrap analysis summary showing the indirect effects of school authority pressures on burnout dimensions via BPN thwarting

\begin{tabular}{lcccc}
\hline & & & \multicolumn{2}{c}{ Bootstrapping BC 95\% } \\
\hline Path & Estimate & $\mathrm{p}$ & Lower & Upper \\
\hline SAP - AT - Exhaustion & .646 & .004 & .220 & 1.110 \\
SAP - AT - Depersonalization & .537 & .013 & .133 & 1.076 \\
SAP - AT - Personal accomplishment & -.151 & .472 & -.516 & .264 \\
SAP - CT - Exhaustion & .414 & .003 & .166 & .751 \\
SAP - CT - Depersonalization & .388 & .002 & .124 & .715 \\
SAP - CT - Personal accomplishment & -.166 & .134 & -.412 & .055 \\
SAP - RT - Exhaustion & .161 & .242 & -.135 & .538 \\
SAP - RT - Depersonalization & .271 & .106 & -.066 & .682 \\
SAP - RT - Personal accomplishment & -.162 & .299 & -.471 & .137 \\
\hline
\end{tabular}

Note: $\mathrm{SAP}=$ School authority pressures; $\mathrm{AT}=$ autonomy thwarting; $\mathrm{CT}=$ competence thwarting; $\mathrm{RT}=$ relatedness thwarting

\section{Invariance test across gender and type of school}

The resulting model was re-analyzed in a multigroup analysis to test its invariance across gender. This analysis was performed by comparing the unconstrained multigroup model $(\chi 2[174]=394.164, \mathrm{p}<.001, \chi 2 / \mathrm{df}=2.27, \mathrm{CFI}=.922, \mathrm{RMSEA}=$ $.06, \mathrm{SRMR}=.07)$ with models constraining regression weights $\left(\chi^{2}[184]=411.559, \mathrm{p}<\right.$ $.001, \chi 2 / \mathrm{df}=2.24, \mathrm{CFI}=.919, \mathrm{RMSEA}=.06, \mathrm{SRMR}=.07)$ and covariances $(\chi 2[185]$ $=412.417, \mathrm{p}<.001, \chi 2 / \mathrm{df}=2.23, \mathrm{CFI}=.919, \mathrm{RMSEA}=.06, \mathrm{SRMR}=.04)$.

Following the same procedure, invariance was tested across teachers working at different type of school (public or private), comparing the unconstrained multigroup 
model $\left(\chi^{2}[174]=364.808, \mathrm{p}<.001, \chi^{2} / \mathrm{df}=2.10, \mathrm{CFI}=.930, \mathrm{RMSEA}=.06, \mathrm{SRMR}=\right.$ $.07)$ with models constraining regression weights $(\chi 2[184]=380.913, \mathrm{p}<.001, \chi 2 / \mathrm{df}=$ $2.07, \mathrm{CFI}=.928, \mathrm{RMSEA}=.06, \mathrm{SRMR}=.07)$ and covariances $(\chi 2[185]=382.346, \mathrm{p}$ $<.001, \chi 2 / \mathrm{df}=2.07, \mathrm{CFI}=.927, \mathrm{RMSEA}=.06, \mathrm{SRMR}=.07)$. Aligned with the recommendation of Cheung and Rensvold (2002), our results $(\Delta \mathrm{CFI}=.03$ in both tests) provide support for the invariance across gender and type of school of the final model.

\section{Discussion}

The aim of this study was to examine the role of psychological need thwarting in mediating PE teachers' work pressures stemming from school authorities and burnout. Teachers' ill-being has been a topic of interest in the literature and several attempts have been made to identify sources of work-related pressures which could affect teachers' health. However, little is known about the specific associations between pressures from school authorities and PE teachers' burnout, via psychological need thwarting. Two predictive models were tested. In the first one, the dependent variable was burnout as a whole; in the second one, the three dimensions of burnout were deemed as three latent variables. Given that the first part of both models (association between teachers' perceptions of pressures stemming from school authorities and need thwarting) was the same, findings relative to this relationship will be firstly discussed. After that, associations between need thwarting and burnout as a whole will be addressed and lastly the section will focus on the findings relative to the associations between each need thwarting and each burnout dimension

\section{PE teachers' perceptions of pressures stemming from authorities and need}

\section{thwarting}


As hypothesized, the relationships between perceived pressure by school authorities and needs thwarting were significant and in the expected direction. These results were consistent with previous studies examining how pressures perceived by teachers affect different outcomes. In this line, there is evidence that pressures "from above" (Pelletier, Séguin-Lévesque, \& Legault, 2002) would not only affect healthrelated constructs among teachers such as burnout, vitality or somatic complaints (Bartholomew et al., 2014; Cuevas et al., 2018), but also teachers' behaviors such as controlling or autonomy-supportive teaching or the use of motivational strategies (Pelletier \& Sharp, 2009; Soenens, Sierens, Vansteenkiste, Dochy, \& Goosens, 2012). Most of the studies addressing this issue among teachers have examined pressures at work as a whole, including time constraints, student performance-based evaluation, and need to conform to colleagues' and authorities' teaching methods or curriculum constraints (Leroy, Bressoux, Sarrazin, \& Troullioud, 2007; Pelletier et al., 2002; Taylor, Ntoumanis, \& Standage, 2008). While it seems justifiable to argue that contextual factors affect teachers' health and behaviors, little is known about the independent role of the different sources of pressures. In this line of inquiry Taylor, Ntoumanis, and Smith (2009) provided an in-depth analysis of how the PE teaching context influenced teachers' motivational strategies towards students from a qualitative perspective. Findings of their study revealed that perceptions of an emphasis on student assessment, as well as time constraints associated with PE lessons, could lead to the use of inadequate teaching strategies as teachers found them to be negative. However, pressure to conform to colleagues' teaching methods was found to be a positive factor since it encouraged a more consistent teaching community. Although, as the authors claim, this finding underscores the importance of exploring individuals' unique experiences, it is questionable whether this conceptualization of pressures from school 
authorities and colleagues could be generalized. To the best of our knowledge, in addition to studies considering a global concept of pressures at work which included pressures to conform to colleagues' teaching methods (e.g., Bartholomew et al., 2014; Taylor et al., 2008), there is one study which focused on pressures exerted by colleagues, parents, and school principals (Soenens et al., 2012). Results from this last study suggested that when teachers experienced these pressures, they were more likely to show psychologically controlling teaching behaviors.

Findings of the present study contribute to the existing literature by examining more fully the role of distinct pressures stemming from school authorities. In an attempt to address the analysis of the independent role of different types of pressures, Cuevas et al. (2018) tested an explanatory model which posited that pressure experienced by teachers when they are evaluated based on their students' academic performance would differentially predict teacher adaptive and maladaptive motivation, well-being, and illbeing. Findings suggested that being evaluated by students' grades predicted teachers' motivation and mental health. Our own results imply that when teachers find themselves pressured to act in a certain way by their school authorities, regardless of the influence of other sources of stress, they are more likely to have their BPN thwarted.

\section{Influence of BPN thwarting on burnout}

As for the association between BPN thwarting and burnout as a whole, the findings of the present study revealed a significant association between each need thwarting and burnout. These results are in line with existing literature. Bartholomew et al. (2014) tested this same association and found that the thwarting of the three needs were associated with burnout. Interestingly, while the three relationships were significant, in both studies the path coefficients were larger in autonomy thwarting followed by competence and relatedness thwarting, respectively. These results reinforce 
the findings by previous literature in which associations between needs satisfaction and burnout had been tested (Abós, Haerens, Sevil, Aelterman, \& García-González, 2018; Van den Berghe et al., 2014) and suggest that, as much as the absence of needs satisfaction may lead to maladaptive experiences, when teachers feel that their needs are being actively undermined, they are also more likely to experience burnout.

The findings of the present study regarding associations between BPN thwarting and burnout dimensions revealed that each need thwarting had a differential role in the prediction of each burnout dimension. Despite being defined as a combination of three components (emotional exhaustion, lack of personal accomplishment, and depersonalization) most of studies carried out in an educational context have considered burnout as a unidimensional construct (e.g., Bartholomew et al., 2014; Fisher, 2011; Richards, Andrew, Hemphill, \& Templin, 2018). While each burnout dimension should be a matter of concern, investigating distinctions between them provides a better understanding of teachers' profiles. The associations relative to each burnout dimension will be discussed.

Our findings revealed that a large portion of variance in emotional exhaustion was predicted by the thwarting of both autonomy and competence. Emotional exhaustion has been suggested to directly and negatively influence perceived autonomy support by students (Shen et al., 2015). The influence that these feelings of fatigue and frustration among teachers might have on learning processes could explain why an issue of current interest has been the understanding of this dimension's antecedents (Cuevas et al., 2018; Soenens et al., 2012). When teachers perceive that they are controlled in the way they do their job or experience situations which make them feel incompetent and do not believe they have chances to show their capacity they are more likely to become tired and feel amotivated to cope with their daily job. A recent study has suggested that 
emotional exhaustion could be predicted by emotional intelligence and unpleasant emotions (Lee, Kwon, \& Richards, 2019). Given that thwarting-needs experiences could lead teachers to feel the aforementioned unpleasant emotions, it would be interesting to analyze how emotional intelligence can affect the associations between needs thwarting and burnout.

With regards to depersonalization, our findings reveal that it might be also predicted by both autonomy and competence thwarting. It is suggested that when teachers feel they are being prevented to act in an autonomous way or feel they are not being given the opportunity to show their competence, are more likely to lose an emotional or cognitive involvement with their work. It might also lead them to show an excessively detached response to certain aspects of the job by actively ignoring the qualities that make students unique and engaging (McCarthy, Kissen, Yadley, Wood, \& Lambert, 2006).

On the other hand, counter to our hypotheses, results revealed that BPN thwarting has limited influence on personal accomplishment. Previous studies have been able to establish the association between thwarting of each BPN and personal accomplishment (Sánchez-Oliva et al., 2014). In a study carried out with coaches (Pulido et al., 2017), it was found that while the dimension of exhaustion was related to the thwarting of each BPN, personal accomplishment showed a significant correlation with competence thwarting only, suggesting that this latter dimension of burnout might not be as strongly related to BPN thwarting as exhaustion. It was particularly surprising in our findings that the competence thwarting could not predict personal accomplishment as this dimension reflects negative feelings of competence and achievement and a tendency to evaluate oneself negatively with respect to work (Maslach, Schaufeli, \& Leiter, 2001). When further examining both dimensions, it can 
be observed that while personal accomplishment tends to focus on personal success due to one's own abilities, competence thwarting refers to work-related characteristics undermining personal feelings of competence. As a matter of fact, an example item to measure personal accomplishment is "I believe I am good at my job", while one of competence thwarting is "There are certain situations which make me feel dull". According to Maslach et al. (2001), reduction of personal accomplishment emerges from a lack of relevant resources whereas both exhaustion and depersonalization are predicted by work overload or social conflict. Therefore, it could be suggested that perceiving that their competence satisfaction is being undermined or thwarted might make teachers feel more exhausted and show more cynical attitudes toward their students. However, this competence thwarting would not affect feelings of accomplishment because teachers might believe that they are as good as they can be.

All in all, while both autonomy and competence thwarting seem to play a role in the prediction of burnout, the findings of the present study suggest that relatedness is not significantly associated with any burnout dimensions. Sánchez-Oliva et al. (2014) found that relatedness thwarting did not significantly predict emotional exhaustion or depersonalization and, surprisingly, positively predicted personal accomplishment. Findings of this same study suggested that relatedness thwarting in PE teachers was not a predictor of amotivation and other studies have found relatedness thwarting to be the least important BPN in the explanation of teachers' burnout (Cuevas et al., 2015) and somatic complaints (Bartholomew et al., 2014).

Considering the above it seems that, despite being one of the three BPN, relatedness has often played a less determinant role than autonomy and competence needs in studies developed among teachers through the lens of the trans-contextual model. As it has been previously suggested, the need for relatedness might not be as determinant as the 
needs for autonomy and competence when it comes to explain personal ill-being (Sánchez-Oliva et al., 2014). Future studies could further explore the role of relatedness in PE teachers

\section{Practical implications}

The current findings highlight the deleterious role of pressures stemming from school authorities for PE teachers. In contrast to some literature which indicates that pressure can be a positive and motivating factor and is often essential in a job (e.g., Ren \& Zhang, 2015), our results suggest that pressures are experienced by teachers as detrimental to their psychological needs and mental health. There are some characteristics of PE which might lead to PE teachers feeling pressured. Considering that PE is a subject which is often taught in a wide and open space, interactions between students are more likely to happen than in other subjects, which might lead students to quarrel. Moreover, PE teachers frequently work in locations which are visible to other teachers and authorities at school. This feature could help to explain why PE teachers feel particularly stressed to conform to certain methodologies in order to maintain discipline. In our view, school authorities should understand and acknowledge the bespoke characteristics of PE and support PE teachers. Such an empathic approach could decrease pressures perceived by teachers to act in a certain manner and, in turn, help to prevent the development of burnout symptoms.

Another possible trigger of perceived pressures is the prescriptive curriculum. The more recent curriculum framework of the different Education Acts in Spain has been criticized for being too closed and controlling (Molina et al., 2016). The teacher is placed in a technical teaching role and forced to comply with a highly materialized curriculum that has not been previously reflected on or discussed by the relevant professional and educational agents. A more flexible curriculum which would allow 
teachers to make some decisions on their practice could decrease the level of pressures stemming from 'above'.

In sum, it seems desirable to erase teachers' ill-being caused by authoritiesrelated pressures that principals could create an autonomy-supportive climate in which teachers have a say in various decisions and are offered opportunities for self-direction. University, as a social change agent, is expected to play an important role in moving evidence-based knowledge closer to the practitioners. In this line, the development of training programs as well as the creation of guidelines by research groups for both administrations and school principals, could strengthen the collaboration between universities and other educational institutions and thus reinforce the link between knowledge and practice.

\section{Limitations and future directions}

Several limitations in the present study should be noted. First, the study was cross-sectional in nature, which prevented us from testing causal relations between pressures stemming from school authorities and teachers' burnout. While experimental studies testing to what extent the implementation of certain strategies from the administration could influence teachers' perceptions of pressures stemming from authorities, would be ideal, it might be difficult to recruit administrators to conduct such study. Therefore, the development of programs to educate school principals about best practices to support their teachers' well-being could be a plausible alternative. Second, the sample of teachers was confined to a single country and a single subject, which prevents us from generalizing current findings. Further research should address how pressures can differently affect teachers' ill-being depending on the country or on the subject they teach. Third, the present study considered pressures stemming from authorities as a general dimension. Nevertheless, several different sources of stress 
could be identified in Spain (such as the perception of a too prescriptive curriculum, the need to conform to certain teaching methods, or the need to teach PE via the medium of English). It would be informative for future investigations to examine how these different sources of pressures might influence teachers' ill-being and, in turn, teachers' behaviors during their classes.

\section{References}

Abós, A., Haerens, L., Sevil-Serrano, J., Morbée, S., Julián, J. A., \& García-González, L. (2019). Does the Level of Motivation of Physical Education Teachers Matter in Terms of Job Satisfaction and Emotional Exhaustion? A Person-Centered Examination Based on Self-Determination Theory. International Journal of Environmental Research and Public Health, 16(16). doi:10.3390/ijerph16162839

Abós, A., Haerens, L., Sevil, J., Aelterman, N., \& García-González, L. (2018). Teachers' motivation in relation to their psychological functioning and interpersonal style: A variable- and person-centered approach. Teaching and Teacher Education, 74, 21-34. doi: https://doi.org/10.1016/j.tate.2018.04.010

Abós, A., Sevil, J., Haerens, L., Aelterman, N., \& García-González, L. (2019). Towards a more refined understanding of the interplay between burnout and engagement among secondary school teachers: A person-centered perspective. Learning and Individual Differences, 72, 69-79. doi: https://doi.org/10.1016/j.lindif.2019.04.008

Acharyya, R., \& Bhattacharya, N. (2020). Research Methodology for Social Sciences. New York, NY.: Routledge.

Akbaba, S. (2014). A comparison of the burnout levels of teachers with different ocupational satisfaction sources. Educational Sciences: Theory and Practice, 14(4), 1253-1261. doi: 10.12738/estp.2014.4.1994

Albarracín, A., Moreno-Murcia, J. A., \& Beltrán-Carrillo, V. J. (2014). La situación actual de la educación física según su profesorado: Un estudio cualitativo con profesores de la Región de Murcia. Cultura, Ciencia y Deporte, 9(27), 225-234.

American Psychological Association. (2002). Ethical principles of psychologists and code of conduct (Amended August 3, 2016): American Psychological Association.

Bagozzi, R. P., \& Edwards, J. R. (1998). A general approach for representing constructis in organizational research Organizational Research Methods, 1(1), 45-87. doi: 10.1177/109442819800100104

Bartholomew, K. J., Ntoumanis, N., Cuevas, R., \& Lonsdale, C. (2014). Job pressure and ill-health in physical education teachers: The mediating role of psychological need thwarting. Teaching \& Teacher Education, 37, 101-107.

Bartholomew, K. J., Ntoumanis, N., Ryan, R. M., \& Thogersen-Ntoumani, C. (2011). Psychological need thwarting in the sport context: Assessing the darker side of athletic experience. Journal of Sport \& Exercise Psychology, 33, 75-102.

Bartholomew, K. J., Ntoumanis, N., \& Thogersen-Ntoumani, C. (2010). Selfdetermination theory and the prediction of ill-being in the sport context: The role 
of psychological need thwarting. Journal of Sport \& Exercise Psychology, 32, S142-S143.

Bentler, P. M., \& Chou, C.-P. (1987). Practical Issues in Structural Modeling.

Sociological Methods \& Research, 16(1), 78-117. doi:

10.1177/0049124187016001004

Bottiani, J. H., Duran, C. A. K., Pas, E. T., \& Bradshaw, C. P. (2019). Teacher stress and burnout in urban middle schools: Associations with job demands, resources, and effective classroom practices. Journal of School Psychology, 77, 36-51. doi: https://doi.org/10.1016/j.jsp.2019.10.002

Brown, T. A. (2015). Confirmatory factor analysis for applied research. New York, NY: Guilford Press.

Browne, M. W., \& Cudeck, R. (1993). Alternative ways of assessing model fit. In K. A. Bollen \& J. S. Long (Eds.), Testing Structural Equation Models (pp. 136-162). Beverly Hills, CA: Sage.

Buckley, D., Abbott, D., \& Franey, J. (2017). An exploration of Irish teachers' experiences of stress. Irish Journal of Applied Social Studies, 17(1), 28-47.

Byrne, B. M. (2001). Structural equation modeling with Amos: Basic concepts, applications, and programming. Mahwah, NJ: Erlbaum.

Byrne, B. M. (2008). Testing for multigroup equivalence of a measuring instrument: A walk through the process. Psicothema, 20(4), 872-882.

Cuevas, R., Ntoumanis, N., Fernandez-Bustos, J. G., \& Bartholomew, K. (2018). Does teacher evaluation based on student performance predict motivation, well-being, and ill-being? Journal of School Psychology, 68, 154-162. doi: https://doi.org/10.1016/j.jsp.2018.03.005

Cuevas, R., Sánchez-Oliva, D., Bartholomew, K. J., Ntoumanis, N., \& García-Calvo, T. (2015). Adaptation and validation of the psychological need thwarting scale in Spanish Physical Education teachers. Spanish Journal of Psychology, 18, 1-9. doi: $10.1017 /$ sjp.2015.56

Cheung, G. W., \& Rensvold, R. B. (2002). Evaluating goodness-of-fit indexes for testing measurement invariance. Structural Equation Modeling, 9(2), 233-255. doi: 10.1207/S15328007SEM0902_5

Fisher, M. H. (2011). Factors influencing stress, burnout, and retention of secondary teachers. Current Issues in Education, 14(1).

Fornell, C., \& Larcker, D. F. (1981). Evaluating structural equations models with unobservable variables and measurement error. Journal of Marketing Research, $18,39-50$.

García-Carmona, M., Marín, M. D., \& Aguayo, R. (2019). Burnout syndrome in secondary school teachers: a systematic review and meta-analysis. Social Psychology of Education, 22(1), 189-208. doi: 10.1007/s11218-018-9471-9

Gil-Monte, P. R. (2002). The factorial validity of the Maslash Burnout inventorygeneral survey (MBI-GS) Spanish version. Salud Pública de México, 44, 33-40.

Gluschkoff, K., Elovainio, M., Kinnunen, U., Mullola, S., Hintsanen, M., KeltikangasJärvinen, L., \& Hintsa, T. (2016). Work stress, poor recovery and burnout in teachers. Occupational Medicine, 66(7), 564-570. doi:10.1093/occmed/kqw086

Hair, J. F., Black, W. C., Babin, B. J., \& Anderson, R. E. (2010). Multivariate data analysis. Englewood Cliffs, NJ: Prentice-Hall.

Hambleton, R. K., \& Patsula, L. (1998). Adapting tests for use in multiple languages and cultures. Social Indicators Research, 45(1), 153-171.

Kidger, J., Brockman, R., Tilling, K., Campbell, R., Ford, T., Araya, R., . . Gunnell, D. (2016). Teachers' wellbeing and depressive symptoms, and associated risk 
factors: A large cross sectional study in English secondary schools. Journal of Affective Disorders, 192, 76-82. doi:10.1016/j.jad.2015.11.054

Kougioumtzis, K., Patriksson, G., \& Stråhlman, O. (2011). Physical education teachers' professionalization: A review of occupational power and professional control. European Physical Education Review, 17(1), 111-129. doi: $10.1177 / 1356336 \mathrm{X} 11402266$

Koustelios, A., \& Tsigilis, N. (2005). The relationship between burnout and job satisfaction among physical education teachers: a multivarite approach. European Physical Education Review, 11(2), 189-203. doi: $10.1177 / 1356336 X 05052896$

Lambert, R., O'Donnell, M., Kusherman, J., \& McCarthy, C. J. (2006). Teacher stress and classroom structural characeristics in preschool settings. In R. Lambert \& C. $\mathrm{J}$. McCarthy (Eds.), Understanding teacher stress in an age of accountaibility (pp. 105-120). Greenwich, CT: Information Age.

Lee, Y. H. (2019). Emotional labor, teacher burnout, and turnover intention in highschool physical education teaching. European Physical Education Review, 25(1), 236-253. doi: 10.1177/1356336x17719559

Lee, Y. H., Kwon, H., \& Richards, K. A. (2019). Emotional intelligence, unpleasant emotions, emotional exhaustion, and job satisfaction in Physical Education teaching. Journal of Teaching in Physical Education, in press. doi: https://doi.org/10.1123/jtpe.2018-0177

Leroy, N., Bressoux, P., Sarrazin, P., \& Troullioud, D. (2007). Impact of teachers' implicit theories and perceived pressures on the establishment of an autonomy supportive climate. European Journal of Psychological of Education, 22(4), 529-545.

Little, T. D., Cunningham, W. A., Shahar, G., \& Widaman, K. F. (2002). To parcel or not to parcel: Exploring the question, weighing the merits. Structural Equation Modeling, 9(2), 151-173.

MacDonald, D. (1995). The role of proletarianization in physical education teachere attrition. Research Quarterly for Exercise \& Sport, 66, 129-141.

Marsh, H. W., Hau, K. T., \& Wen, Z. (2004). In search of golden rules: Comment on hypothesis-testing approaches to setting cutoff values for fit indexes and dangers in overgeneralizing hu and Bentler's (1999) findings. Structural Equation Modeling, 11(3), 320-341.

Maslach, C., \& Leiter, M. P. (2005). Stress and burnout: the critical research. In C. L. Cooper (Ed.), Handbook of stress medicine and health (pp. 155-168). Lancaster, UK: CRC Press.

Maslach, C., Schaufeli, W. B., \& Leiter, M. P. (2001). Job burnout. Annual Review of Psychology, 53, 397-422. doi: 10.1146/annurev.psych.52.1.397

Matsunaga, M. (2008). Item Parceling in Structural Equation Modeling: A Primer. Communication Methods and Measures, 2(4), 260-293. doi: 10.1080/19312450802458935

McCarthy, C. J., Kissen, D., Yadley, L., Wood, T., \& Lambert, R. G. (2006). Relationship of teachers' preventive coping resources to burnout symptoms. In R. G. Lambert \& C. J. McCarthy (Eds.), Understanding teacher stress in an age of accountability (pp. 179-213). Greenwich, CT: Information Age.

Molina, P., Valenciano, J., \& Úbeda-Colomer, J. (2016). El diseño curricular de la Educación Física en España: Una revisión crítica desde la LOGSE a la LOMCE. Cultura, Ciencia y Deporte, 11(32), 97-106. 
O'Connor, A., \& Macdonald, D. (2002). Up close and personal on physical education teachers' identity: Is conflict an issue? Sport, Education and Society, 7, 37-54.

Pelletier, L., Séguin-Lévesque, C., \& Legault, L. (2002). Pressure from above and pressure from below as determinants of teachers' motivation and teaching behaviors. Journal of Educational Psychology, 94(1), 186-196. doi: 10.1037//0022-0663.94.1.186

Pelletier, L., \& Sharp, E. (2009). Administrative pressures and teachers' interpersonal behaviour in the classroom. Theory and Research in Education, 7(2), 174-183.

Prieto, M., \& Bermejo, L. (2006). Contexto laboral y malestar docente en una muestra de profesores de Secundaria. Revista de Psicología del Trabajo y de las Organizaciones, 22(1), 45-73.

Pulido, J. J., Sánchez-Oliva, D., González-Ponce, I., \& García-Calvo, T. (2017). Frustración de las necesidades psicológicas, motivación y burnout en entrenadores: Incidencia de la formación. Revista de Psicología del Deporte, 26(1), 27-36.

Ren, F., \& Zhang, J. (2015). Job Stressors, Organizational Innovation Climate, and Employees' Innovative Behavior. Creativity Research Journal, 27(1), 16-23. doi: 10.1080/10400419.2015.992659

Richards, R., Andrew, K., Hemphill, M. A., \& Templin, T. J. (2018). Personal and contextual factors related to teachers' experience with stress and burnout. Teachers and Teaching, 24(7), 768-787. doi: 10.1080/13540602.2018.1476337

Ryan, R. M., \& Deci, E. L. (2020). Intrinsic and extrinsic motivation from a selfdetermination theory perspective: Definitions, theory, practices, and future direction. Contemporary Educational Psychology. doi: https://doi.org/10.1016/j.cedpsych.2020.101860

Sáenz-López, P., Almagro, B. J., \& Ibáñez, S. J. (2011). Describing problems experienced by Spanish novice physical education teachers. The Open Sports Sciences Journal, 4, 1-9.

Sánchez-Oliva, D., Sánchez-Miguel, P. A., Pulido, J. J., López-Chamorro, J. M., \& Cuevas, R. (2014). Motivation and burnout in physical education teachers: incidence of thwarting of the basic psychological needs. Cuadernos de Psicología del Deporte, 14(3), 75-82.

Schaufeli, W. B., Leiter, M. P., Maslach, C., \& Jackson, S. E. (1996). The MBI-general survey. In C. Maslach, S. E. Jackson \& M. P. Leiter (Eds.), Maslach Burnout Inventory. Manual (3rd ed. ed., pp. 19-26). Palo Alto, CA: Consulting Psychologists Press.

Shen, B., McCaughtry, N., Martin, J., Garn, A., Kulik, N., \& Fahlman, M. (2015). The relationship between teacher burnout and student motivation. British Journal of Educational Psychology, 85, 519-532. doi: 10.1111/bjep.12089

Smith, D., \& Leng, G. W. (2003). Prevalence and Sources of Burnout in Singapore Secondary School Physical Education Teachers. Journal of Teaching in Physical Education, 22(2), 203-218. doi: 10.1123/jtpe.22.2.203

Soenens, B., Sierens, E., Vansteenkiste, M., Dochy, F., \& Goosens, L. (2012). Psychologically controlling teaching: Examining outcomes, antecedents, and mediators. Journal of Educational Psychology, 104(1), 108-120. doi: $10.1037 / \mathrm{a} 0025742$

Spittle, M., Kremer, P., \& Sullivan, S. (2015). Burnout in secondary school physical education teaching. Series Physical Education and Sport, 13, 33-43.

Stebbings, J., Taylor, I. M., Spray, C., \& Ntoumanis, N. (2012). Antedecents of perceived coach interpersonal behaviors: The coaching environment and coach 
psychological well- and ill-being. Journal of Sport \& Exercise Psychology, 34, 481-502.

Taylor, I. M., Ntoumanis, N., \& Smith, B. (2009). The context as a determinant of teacher motivational strategies im physical education. Psychology of Sport \& Exercise, 10, 235-243.

Taylor, I. M., Ntoumanis, N., \& Standage, M. (2008). A self-determination theory approach to understanding the antecedents of teachers' motivational strategies in physical education. Journal of Sport \& Exercise Psychology, 30(1), 75-94.

van Aart, I., Hartman, E., Elferink-Gemser, M., Mombarg, R., \& Visscher, C. (2017). Relations among basic psychological needs, PE-motivation and fundamental movement skills in 9-12-year-old boys and girls in Physical Education. Physical Education and Sport Pedagogy, 22(1), 15-20. doi: 10.1080/17408989.2015.1112776

Van den Berghe, L., Soenens, B., Aelterman, N., Cardon, G., Tallir, I. B., \& Haerens, L. (2014). Within-person profiles of teachers' motivation to teach: Associations with need satisfaction at work, need-supportive teaching, and burnout. Psychology of Sport and Exercise, 15(4), 407-417. doi: https://doi.org/10.1016/j.psychsport.2014.04.001

Van den Berghe, L., Soenens, B., Vansteenkiste, M., N., A., Cardon, G., Tallir, I. B., \& Haerens, L. (2013). Observed need-supportive and need-thwarting teaching behavior in physical education: Do teachers' motivational orientations matter? Psychology of Sport \& Exercise, 14, 650-661. doi: 10.1016/j.psychsport.2013.04.006

van Sonderen, E., Sanderman, R. n., \& Coyne, J. C. (2013). Ineffectivenss of Reverse Wording of Quesionnaire Items: Let's Learn from Cows in the Rain. PLOS one, 8(7). doi: 10.1371/journal.pone.0068967

Vansteenkiste, M., Ryan, R. M., \& Soenens, B. (2020). Basic psychological need theory: Advancements, critical themes, and future directions. Motivation and emotion, 44(1), 1-31. doi: 10.1007/s11031-019-09818-1

Wang, Y. A., \& Rhemtulla, M. (in press). Power Analysis for Parameter Estimation in Structural Equation Modeling: A Discussion and Tutorial Advances in Methods and Practices in Psychological Science.

Whipp, P.R., Tan, G., \& Yeo, P.T. (2007). Experienced physical education teachers reaching their "use-bydate": powerless and disrespected. Research Quarterly for Exercise and Sport, 78, 487-499. 


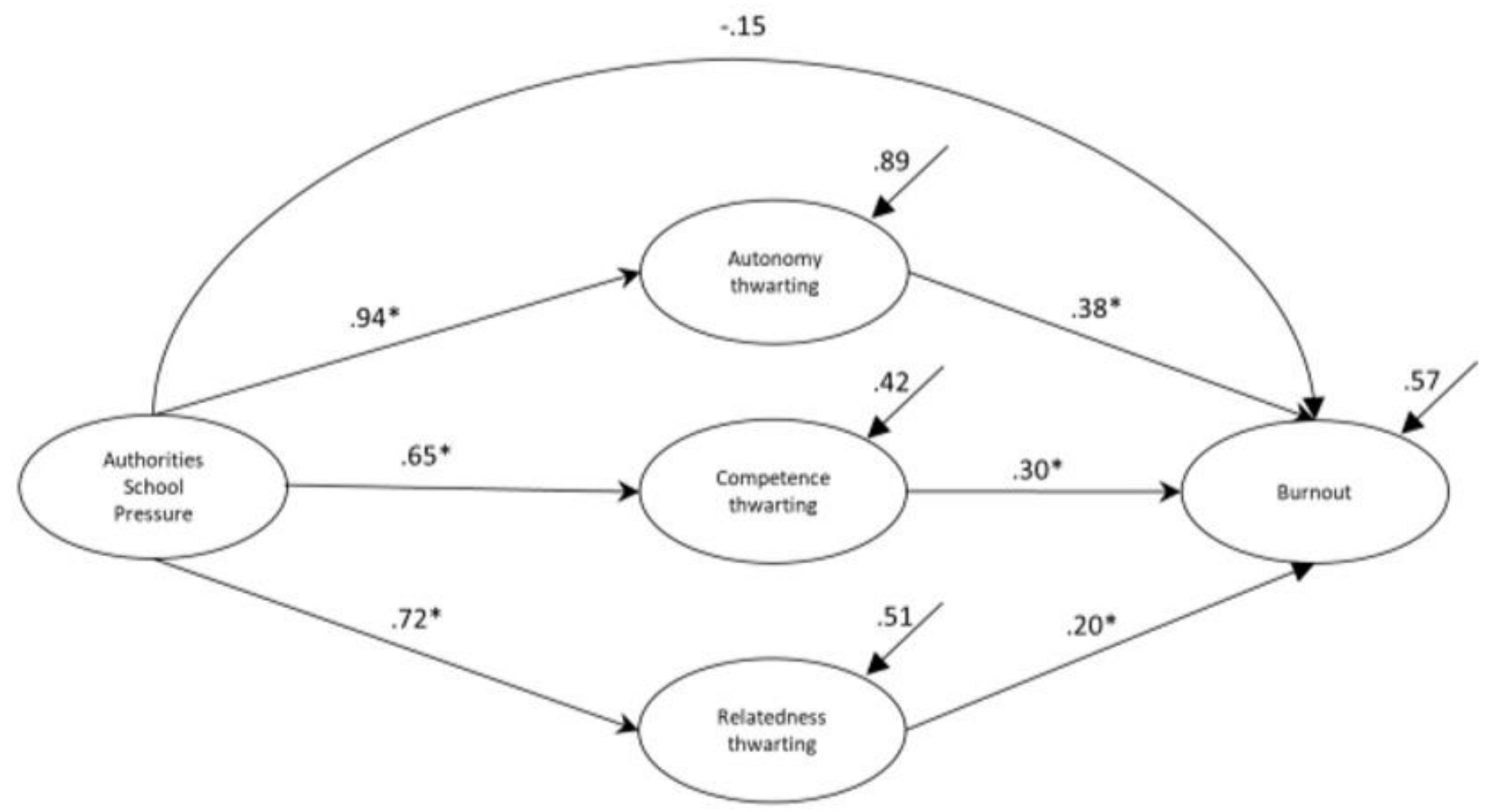

Figure 1. Explanatory model for unidimensional burnout. All parameters are standardized. Explained variances $\left(R^{2}\right)$ are shown on the small arrows.

$$
{ }^{*} p<.05
$$




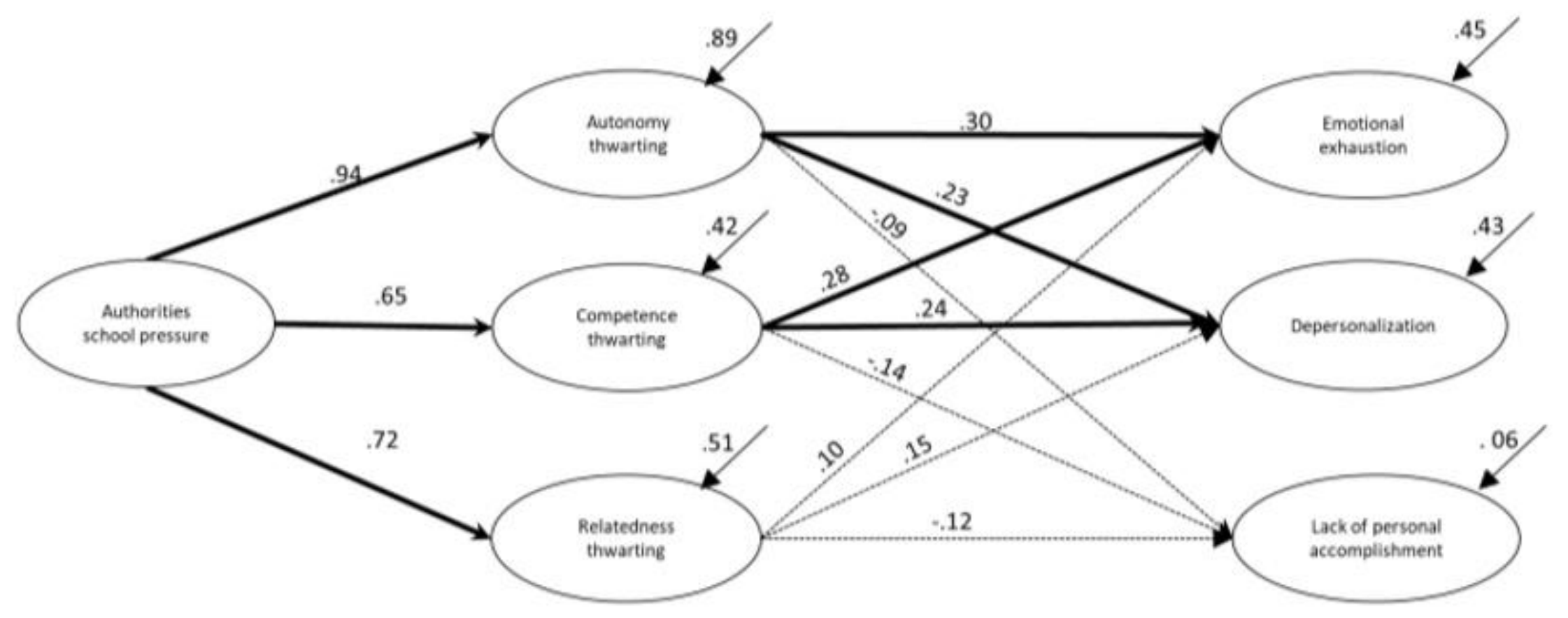

Figure 2. Explanatory model for multidimensional burnout. All parameters are standardized. Dotted lines represent non-significant parameters. Explained variances are shown on the small arrows $\left(R^{2}\right)$. 
